\title{
EFICIÊNCIA DE DIFERENTES HERBICIDAS NA DESSECAÇÃO DE TRÊS ESPÉCIES VEGETAIS PARA COBERTURA DO SOLO
}

\author{
Luiz C. F. Souza', Tarcísio de O. Valente ${ }^{1}$, André L. Melhorança ${ }^{2}$, \\ Francisco de Assis R. Pereira ${ }^{3}$ e Antônio C. Júnior ${ }^{1}$
}

\author{
${ }^{1}$ Universidade Federal de Mato Grosso do Sul. Caixa Postal 322. Dourados, MS 79804-970 \\ ${ }^{2}$ Embrapa Agropecuária Oeste. Caixa Postal 661. Dourados, MS 79804-970 \\ ${ }^{3}$ Empaer. Caixa Postal 472. Campo Grande, MS 79831-902
}

\section{RESUMO}

Com o objetivo de avaliar a eficiência de diferentes herbicidas dessecantes e doses, foi conduzido um experimento no Núcleo Experimental de Ciências Agrárias da Universidade Federal de Mato Grosso do Sul, no município de Dourados, MS, no ano agrícola 1995/96. Utilizou-se o delineamento experimental de blocos casualizados e os tratamentos foram compostos por três espécies vegetais [aveia-preta (Avena strigosa), milheto (Pennisetum typhoydes) e capim-marmelada (Brachiaria plantaginea $)$ e quatro herbicidas dessecantes em três doses cada um: paraquat $(0,30,0,40$ e $0,60 \mathrm{~kg} / \mathrm{ha})$, glyphosate $(0,72$, 1,08 e 1,44 kg/ha), sulfosate $(0,96,1,44$ e $1,92 \mathrm{~kg} / \mathrm{ha})$ e glyphosate+2,4-D $(0,54+0,67,0,54+1,0$ e $0,54+1,34 \mathrm{~kg} / \mathrm{ha}) . \mathrm{Os}$ herbicidas glyphosate, sulfosate e a mistura glyphosate+2,4-D foram eficientes na dessecação das três espécies em todas as doses utilizadas. Houve rebrota das plantas de milheto e de capim-marmelada aos 36 dias após a aplicação de paraquat.

Palavras-chave: herbicida dessecante, milheto, capim-marmelada, aveia-preta.

\section{ABSTRACT \\ Efficacy of selected herbicides in the desiccation of three plant species for soil cover}

An experiment was carried out with the objective of evaluating the efficiency of selected herbicides in the desiccation of three plant species in Dourados (MS), Brazil, in 1995/96. A randomized block design was used in three plant species: black oat (Avena strigosa), millet (Pennisetum typhoydes) and Brachiaria plantaginea, with four herbicides in three rates: paraquat $(0.30,0.40$ and $0.60 \mathrm{~kg} / \mathrm{ha})$, glyphosate $(0.72,1.08$ and $1,44 \mathrm{~kg} / \mathrm{ha})$, sulfosate $(0.96,1.44$ and $1.92 \mathrm{~kg} / \mathrm{ha})$ and glyphosate+2,4-D $(0.54+0.67,0.54+1.0$ and $0.54+1.34 \mathrm{~kg} / \mathrm{ha})$. The herbicides glyphosate, sulfosate and the mixture glyphosate $+2,4-\mathrm{D}$ were efficient to desiccate the three species in all doses. The plants of millet and Brachiaria plantaginea showed a re-growth after 36 days of the application of paraquat.

Key words: black-oat, Brachiaria plantaginea, desiccation, herbicide, millet.

\section{INTRODUÇÃO}

$\mathrm{Na}$ literatura são muitos os trabalhos de pesquisa que apontam vantagens decorrentes da utilização de plantio direto nas propriedades físicas, químicas e biológicas do solo, no rendimento das culturas e no controle da erosão (Montoya,1982; Vieira e Muzilli, 1984; Muzilli, 1985; Vieira, 1985; Sidiras e Pavan, 1986). É oportuno lembrar que um solo coberto com palha estará protegido da ação nociva do impacto das gotas de chuva que iniciam o processo de erosão; dessa forma a cobertura com palha reduzirá as perdas de água e solo. O solo estará também protegido da insolação direta que eleva a temperatura a níveis prejudiciais para grande parte das atividades biológicas. Um solo com adequada camada de palha terá, ainda, menores taxas de evaporação, ou seja, perderá menos água, mantendo-se úmido por maior período de tempo (Salton, 1993). 
A importância da palha na agricultura racional é conhecida por muitos agricultores de Mato Grosso do Sul e é por isso que se tem utilizado em larga escala culturas para a cobertura do solo, em épocas de entressafra, principalmente por aqueles que são adeptos ao sistema de plantio direto na palha (Salton, 1993; Carneiro e Borges, 1994).

Uma das dificuldades encontrada pelos agricultores do Estado é a permanência da palha sobre o solo em quantidade suficiente (cerca de 5 ton/ha) para que permaneça durante $\mathrm{o}$ ano todo. Isto decorre das condições ambientais existentes, que favorecem elevadas taxas de decomposição de materiais orgânicos (Salton, 1993).

Dentre as alternativas para cobertura do solo, o milheto (Pennisetum typhoides (Burn) Staffet Hulb) é muito utilizado no sistema de plantio direto, em vista do rápido desenvolvimento vegetativo e da abundante produção de massa verde, tornando-o competitivo e supressor de plantas infestantes. Outra alternativa é a aveia-preta (Avena strigosa Schieb.), por sua adaptação e boa produção de palha (Pitol, 1993). O capim-marmelada (Brachiaria plantaginea (Link) Hitch.) pode ser também uma opção para a semeadura direta na região, pois a sua infestação é comum, apresentando desenvolvimento bastante acelerado, com boa produção de massa vegetal (Lorenzi, 1994).

Estudos de doses de sulfosate (480 g/ha), glyphosate (720 g/ha), 2,4-D (720 g/ha) e aplicados com e sem a adição de uréia, e as mistura de sulfosate + 2,4-D (480+720 g/ha) e glyphosate $+2,4-\mathrm{D}(720+720 \mathrm{~g} / \mathrm{ha})$, indicaram que a adição de uréia, de 2,4-D, e especialmente de uréia + 2,4-D aumentou a velocidade de aparecimento de sintomas para o sulfosate e glyphosate. Estas diferenças diminuíram com o tempo, sendo que aos 14 dias após a aplicação, os tratamentos não diferiram significativamente entre si, com excelente dessecação do milheto.

Um dos fatores que viabilizou o plantio direto foi o surgimento de novos herbicidas, destacando-se os de ação total (dessecantes), os quais viabilizam a semeadura na palha. Entretanto, estudos de doses e de misturas dos diferentes ingredientes ativos são de fundamental importância para as várias espécies utilizadas para a cobertura do solo. Assim, a presente pesquisa objetiva avaliar o efeito de diferentes herbicidas e doses para dessecação de milheto, aveia-preta e capim-marmelada, visando o plantio direto na palha.

\section{MATERIAL E MÉTODOS}

O experimento foi realizado em Latossolo Roxo distrófico, no Núcleo Experimental de Ciências Agrárias da Universidade Federal de Mato Grosso do Sul, no ano agrícola 1995/96, em Dourados-MS, situado na latitude $22^{\circ} 14^{\prime}$ sul, longitude $54^{\circ} 49^{\prime}$ oeste e altitude de 452 metros, com precipitações médias anuais em torno de $1400 \mathrm{~mm}$. O solo é classificado como Latossolo Roxo textura argilosa.

Para avaliar a eficiência dos herbicidas dessecantes foram conduzidos três experimentos. O primeiro foi realizado utilizando-se o milheto (Pennisetum thyphoides), o segundo o capim-marmelada (Brachiaria plantaginea) e o terceiro a aveia-preta (Avena strigosa) para a cobertura do solo.

O delineamento experimental adotado foi o de blocos casualizados, em esquema fatorial $4 \times 3$, constituído por quatro herbicidas, em três doses de aplicação: paraquat $(0,30$, $0,40$ e $0,60 \mathrm{~kg} / \mathrm{ha})$ glyphosate $(0,72,1,08$ e $1,44 \mathrm{~kg} / \mathrm{ha})$, sulfosate $(0,96,1,44$ e $1,92 \mathrm{~kg} / \mathrm{ha})$ e glyphosate $+2,4-\mathrm{D}$ $(0,54+0,70,0,54+1,00$ e $0,54+1,34 \mathrm{~kg} / \mathrm{ha})$, totalizando 12 tratamentos, com quatro repetições. A área de cada parcela foi de $36 \mathrm{~m}^{2}(12 \mathrm{~m} \times 3 \mathrm{~m})$.

O preparo do solo para milheto e capim-marmelada foi realizado na segunda quinzena de setembro com uma gradagem pesada e à véspera da semeadura foi feita uma gradagem leve. A semeadura do milheto foi realizada manualmente a lanço, no dia 06/10/95, seguida de uma gradagem leve para incorporação da semente. Para o capim-marmelada não foi necessário fazer-se a semeadura, em função de sua ocorrência natural nas parcelas. O preparo do solo para aveia-preta foi semelhante ao adotado para o milheto, sendo a semeadura realizada mecanicamente, no dia 29/03/96.

As aplicações dos herbicidas dessecantes no capimmarmelada e no milheto, foram feitas no dia 6 de dezembro de 1995 , quando mais de $85 \%$ das plantas de milheto encontravam-se em floração, com altura média de $1,65 \mathrm{~m}$. O capim-marmelada apresentava $50 \%$ das plantas em floração, com altura média em torno de $0,5 \mathrm{~m}$. A dessecação da aveiapreta ocorreu no dia 25 de julho de 1996, com as plantas em plena floração, ou seja, acima de $90 \%$ e altura em torno de $0,60 \mathrm{~m}$.

Utilizou-se pulverizador tratorizado para as aplicações, da marca Jacto, com capacidade para 400 litros de calda, equipado com barra de 3,5 m de largura munida com 7 bicos do tipo leque 110.03, espaçados de $50 \mathrm{~cm}$, com pressão de $2,81 \mathrm{~kg} / \mathrm{cm}^{2}$, que proporcionou uma vazão de $200 \mathrm{l} / \mathrm{ha}$. O equipamento foi regulado para pulverizar em torno de $50 \mathrm{~cm}$ acima das espécies a serem dessecadas.

A aplicação na aveia-preta iniciou-se às 15:30 horas, com umidade relativa em torno de $60 \%$ e temperatura de $27^{\circ} \mathrm{C}$. Para a dessecação de milheto e de capim-marmelada a aplicação ocorreu das 16:00 às 19:00 horas, com umidade relativa em torno de $70 \%$, à temperatura de $22^{\circ} \mathrm{C}$, sem vento.

As avaliações da eficiência dos herbicidas dessecantes sobre milheto, capim-marmelada e aveia-preta foram realizadas aos 12 e 36 DAA (dias após aplicação) dos herbicidas. Realizou-se avaliação visual da eficiência de dessecação, 
adotando escala de 0 a 100 , onde zero corresponde a nenhum efeito do herbicida e 100 à morte total das plantas (Tabela 1), conforme metodologia adotada pelo EWRC (1964).

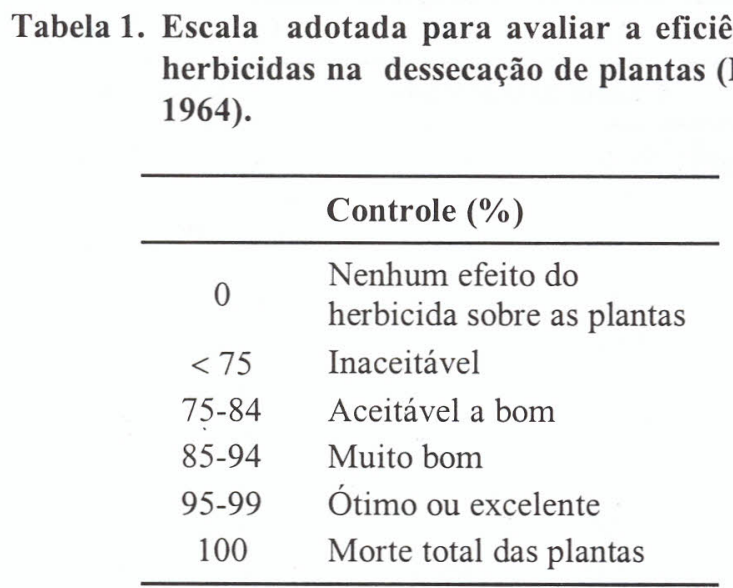

\section{RESULTADOS E DISCUSSÃO}

Observa-se na Tabela 2 que o milheto, o capim-marmelada e a aveia-preta foram dessecados de forma eficiente por todos os herbicidas sistêmicos estudados, aos 12 DAA (dias após a aplicação), embora para o milheto e o capimmarmelada, a mistura glyphosate $+2,4 \mathrm{D}$, nas doses menores, foi considerada de acordo com a escala adotada, com eficiência variando de aceitável a bom (Tabela 1). Porém, na avaliação realizada aos $36 \mathrm{DAA}$, estas diferenças deixaram de existir, mostrando que os herbicidas sistêmicos continuaram agindo após a primeira avaliação.

Pires et al. (1997) verificaram que o sulfosate e o glyphosate foram eficientes na dessecação de Brachiaria brizantha, nas doses de 4,66, 5,01, 5,10 e 6,85 1 de p.c./ha. Melhorança et al. (1997) obtiveram também excelente controle de $B$. brizantha, $B$. humidicola e $B$. decumbens nas doses de 3,0, 4,0 e 5,0 1/ha.

De acordo com Barros (1995), o sulfosate e o glyphosate, na dose de 0,3 e $0,4 \mathrm{~kg} / \mathrm{ha}$, mostraram ótimo controle da $B$. decumbens, não havendo diferenças significativas entre herbicidas e doses. O glyphosate e o sulfosate na dose $0,72 \mathrm{~kg} /$ ha mostraram comportamento excelente na dessecação do milheto. A adição de uréia + 2,4-D aumentou a velocidade de aparecimento dos sintomas do glyphosate e sulfosate nas plantas.

A redução da dose de glyphosate para $0,54 \mathrm{~kg} / \mathrm{ha}$, em mistura com o herbicida $2,4-\mathrm{D}$, não afetou a eficiência do produto em comparação com o glyphosate isolado em doses maiores, na dessecação das três espécies estudadas, principalmente aos 36 DAA. Aparentemente, o 2,4-D nas doses utilizadas melhorou a eficiência do glyphosate. No entanto, Ferri et al. (1997) utilizando doses menores de 2,4-D (200 g/ ha) em mistura com glyphosate não obtiveram melhoria na eficiência do produto na dessecação de gramíneas em campos nativos.

Por outro lado, o paraquat em todas as doses estudadas apresentou uma eficiência considerada muito boa na dessecação do milheto e da aveia-preta na avaliação realizada aos $12 \mathrm{DAA}$, e de aceitável a boa para o capim-marmelada. Mas aos 36 DAA a sua eficiência foi considerada inaceitável para o milheto e o capim-marmelada, com rebrota bastante acentuada das plantas. Porém, para a aveia-preta o paraquat teve ótima eficiência aos $36 \mathrm{DAA}$. Este comportamento pode ser atribuído ao fato do paraquat ter modo de ação por contato, matando a parte área das plantas poucos dias após sua aplicação. Como as condições climáticas foram favoráveis, com chuvas freqüentes à partir do terceiro dia da aplicação, a rebrota das plantas de milheto e capim-marmelada foi bastante favorecida, conforme o observado aos 36 DAA (Tabela 2). Os demais herbicidas, tanto para o capim-marmelada como para o milheto, tiveram eficiência de muito boa a excelente em todas as doses utilizadas (Tabela 2). Esses resultados confirmam as observações de Goellener (1989).

O melhor comportamento do paraquat na dessecação da aveia-preta pode ser atribuído ao menor desenvolvimento das plantas, decorrente de veranicos durante o estádio vegetativo da cultura (junho e julho). Outro fator que possivelmente tenha contribuído foi a ausência de chuvas após a aplicação do produto durante o período das avaliações.

Os herbicidas paraquat, glyphosate, sulfosate e a mistura glyphosate $+2,4 \mathrm{D}$ foram eficientes na dessecação do milheto e do capim-marmelada em todas as doses utilizadas. No entanto, houve rebrota destas plantas na avaliação realizada aos 36 dias após aplicação do paraquat. A quantidade de palha de milheto e do capim-marmelada, sobre a superfície do solo, diminui acentuadamente ao final de sete meses.

Por outro lado, Carneiro e Borges (1995) obtiveram excelente eficiência na dessecação do milheto com paraquat, com duas pulverizações seqüenciais, com intervalo de oito dias entre as aplicações, na dose de 0,3 e 0,2 kg/ha.

\section{CONCLUSÕES}

- O sulfosate e o glyphosate puro ou em mistura com 2,4-D foram eficientes na dessecação de aveia-preta, milheto e capim-marmelada;

- O paraquat não foi eficiente na dessecação de milheto e de capim-marmelada, com rebrota destas plantas aos 36 dias após a aplicação;

- A aveia-preta foi dessecada eficientemente por todos os herbicidas acima mencionados. 
Tabela 2. Efeito de dessecantes no controle de milheto (Pennisetum typhoides), capim-marmelada (Brachiaria plantaginea) e aveia-preta (Avena strigosa), aos 12 e 36 DAA (dias após aplicação). Dourados-MS, 1998.

\begin{tabular}{|c|c|c|c|c|c|c|c|}
\hline \multirow{4}{*}{ Tratamento } & \multirow{4}{*}{$\begin{array}{c}\text { Dose } \\
\text { (kg/ha) }\end{array}$} & \multicolumn{6}{|c|}{ Controle (\%) } \\
\hline & & \multicolumn{6}{|c|}{ Dias Após Aplicação } \\
\hline & & 12 & 36 & 12 & 36 & 12 & 36 \\
\hline & & \multicolumn{2}{|c|}{ Milheto } & \multicolumn{2}{|c|}{ Capim-marmelada } & \multicolumn{2}{|c|}{ Aveia-preta } \\
\hline Glyphosate $^{2}$ & 0,72 & $96 \mathrm{a}^{1}$ & $97 \mathrm{a}^{1}$ & $91 \mathrm{ab}^{1}$ & $99 \mathrm{a}^{1}$ & $97 a b^{1}$ & $98 \mathrm{ab}^{1}$ \\
\hline Glyphosate & 1,08 & 96 a & 97 a & $91 \mathrm{ab}$ & 99 a & $96 a b c$ & $98 \mathrm{ab}$ \\
\hline Glyphosate & 1,44 & $97 \mathrm{a}$ & $98 \mathrm{a}$ & $95 \mathrm{a}$ & $99 \mathrm{a}$ & $97 \mathrm{ab}$ & $97 \mathrm{abc}$ \\
\hline Paraquat ${ }^{3}$ & 0,30 & $93 \mathrm{ab}$ & $4 \mathrm{c}$ & $78 \mathrm{c}$ & $1 \mathrm{c}$ & $96 \mathrm{abc}$ & $96 \mathrm{bc}$ \\
\hline Paraquat & 0,40 & $94 \mathrm{ab}$ & $19 \mathrm{bc}$ & $84 \mathrm{bc}$ & $7 \mathrm{c}$ & $98 \mathrm{ab}$ & $95 \mathrm{c}$ \\
\hline Paraquat & 0,60 & $96 \mathrm{a}$ & $36 \mathrm{~b}$ & $90 \mathrm{ab}$ & $43 \mathrm{~b}$ & $99 \mathrm{a}$ & $96 \mathrm{bc}$ \\
\hline Sulfosate ${ }^{4}$ & 0,96 & $90 \mathrm{ab}$ & $99 \mathrm{a}$ & $86 \mathrm{abc}$ & $99 \mathrm{a}$ & $96 \mathrm{abc}$ & $99 \mathrm{a}$ \\
\hline Sulfosate & 1,44 & $94 \mathrm{ab}$ & $99 \mathrm{a}$ & $86 \mathrm{abc}$ & 99 a & $97 \mathrm{ab}$ & 99 a \\
\hline Sulfosate & 1,92 & $96 \mathrm{a}$ & 99 a & $88 \mathrm{abc}$ & 99 a & $97 \mathrm{ab}$ & 99 a \\
\hline Glyphosate $+2,4 D^{5}$ & $0,54+0,67$ & $84 \mathrm{~b}$ & $94 \mathrm{a}$ & $82 \mathrm{bc}$ & $99 \mathrm{a}$ & $93 c$ & $96 \mathrm{bc}$ \\
\hline Glyphosate + 2,4D & $0,54+1,00$ & $86 \mathrm{ab}$ & $99 \mathrm{a}$ & $84 \mathrm{bc}$ & $99 \mathrm{a}$ & $94 \mathrm{bc}$ & $96 \mathrm{bc}$ \\
\hline Glyphosate $+2,4 \mathrm{D}$ & $0,54+1,34$ & $91 \mathrm{ab}$ & $99 \mathrm{a}$ & $86 a b c$ & $99 \mathrm{a}$ & $96 \mathrm{abc}$ & $96 \mathrm{bc}$ \\
\hline C. V. $(\%)$ & - & 2,7 & 14,6 & 6,0 & 8,8 & 1,2 & 1,4 \\
\hline
\end{tabular}

${ }^{1}$ Médias seguidas por mesma letra na coluna não diferem entre si pelo teste de Tukey, ao nível de $5 \%$ de probabilidade.

Produto Comercial: ${ }^{2}$ Roundup, ${ }^{3}$ Gramoxone, ${ }^{4}$ Zapp, ${ }^{5}$ Roundup + DMA 806.

\section{LITERATURA CITADA}

CARNEIRO, J. 0.F.; BORGES, E. P. Manejo de pastagem de capim braquiária (Brachiaria brizantha) com glyphosate, visando o plantio direto na palha. Maracajú: Fundação MS, 1995. 3p.

EUROPEAN WEED RESEARCH COUNCIL-EWRC. Methods in weed research. Weed Research, Oxford, v. 4, p. 88, 1964.

GOELLENER, C. I. ; Ecotoxologia e toxocolgia de herbicida. Passo Fundo: Gráfica e Editora UPF, 1989. 93 p. ilustrada.

LORENZI, H. Manual de identificação e controle de plantas daninhas: plantio direto e convencional. 4 ed. Nova Odessa: Plantarum, 1994.

MONTOYA, L J. Aspectos da economicidade do manejo do solo em plantio direto. Londrina: IAPAR, 1984. 19 p. (Informe de Pesquisa, 57).
MUZILLI, O. O plantio direto no Brasil. In: ATUALIZAÇÃO EM PLANTIO DIRETO, 1985. cap. 1, p. 3 - 16.

PITOL, C. Espécies para cobertura do solo no Mato Grosso do Sul. In: PLANTIO DIRETO NO BRASIL. Passo Fundo: Aldeia Norte, 1993. p. 166.

SALTON, J. C. Alternativas para produzir palha no Mato Grosso do Sul. In: PLANTIO DIRETO NO BRASIL. Passo Fundo: Aldeia Norte, 1993. p. 16

SIDIRAS, N.; PAVAN, M. A. Influência do sistema de manejo na temperatura do solo. Revista Brasileira de Ciência do Solo, Campinas, v.10, n. 3, p. 181-184, 1986.

VIEIRA, M. J. Comportamento físico do solo em plantio direto. In: ATUALIZAÇÃO EM PLANTIO DIRETO, 1985. cap. 8, p. 163 - 179.

VIEIRA, M. J.; MUZILLI, O. Características físicas de um Latossolo Vermelho Escuro sob diferentes sistemas de manejo. Pesquisa Agropecuária Brasileira, Brasília, v. 19, n. 7, p.189-191. 1984. 